\title{
Canto e Palavra emanando de Igitur
}

Rosie MeHOUdAR

Percebe-se a fonte do canto nas transformações pelas quais passa o personagem Igitur, mesmo se "canto" não é uma palavra do conto Igitur ou la Folie d'Elbehnon ${ }^{1}$, mas chave em textos posteriores. Igitur integraria a gênese da noção mallarmeana de canto. Na parte "Le coup de dés"2 do conto, uma pre-dicção (predição em francês é "prédiction") é pro-ferida (Oc1, p. 841): um antes da voz é ligado à voz... Etimologicamente pro-ferir quer dizer "levar para diante". A pedraconsciência surgida na parte anterior ("Il quitte la chambre" ${ }^{3}$ ) do conto é propagada pela palavra que convoca o Outro - ali, porém, já implicada. O tema principal será então a palavra, tácita ou proferida ${ }^{4}$, no conto Igitur. Um caminho entre "uma antiga palavra" e o canto será proposto. À palavra, constituinte do sujeito, se articulam, em diferentes níveis, imagem corpórea e morte da imagem. Por meio da análise dos principais lances temáticos de "Il quitte la chambre" e de outras partes do conto, vislumbra-se a constituição do sujeito afim à propagação infinita da linguagem. Uma hipótese de interpretação da palavra enigmática "Elbehnon" é proposta: suas sílabas, em hebraico, remeteriam a funções chave do processo de criação. 
Fala-se frequentemente de Igitur como de um conto filosófico. Igitur não foi publicado por Mallarmé, só tendo sido descoberto e editado por seu genro muitos anos depois de sua morte ${ }^{5}$. Mesmo tão enigmático, era talvez por demais explícito dos trajetos filosóficos e pessoais de seu autor. Quando, em 1882, um amigo, Charles Morice, lhe pediu uma página sobre "a filosofia na poesia", o poeta escreveu:

\begin{abstract}
Je révère l'opinion de Poe, nul vestige d'une philosophie, l'éthique ou la métaphysique, ne transparaîtra; j'ajoute qu'il la faut, incluse ou latente. Éviter quelque réalité d'échafaudage demeuré autour de cette architecture spontanée et magique, n'y implique pas le manque de puissants calculs et subtils; mais on les ignore, eux mêmes se font, mystérieux exprès. Le chant jaillit de source innée, antérieure à un concept, si purement que refléter, au dehors, milles rythmes d'images. Quel génie pour être un poëte; quelle foudre d'instinct renfermer, simplement la vie, vierge, en sa synthèse et loin illuminant tout. L'armature intellectuelle du poème se dissimule et tient - a lieu dans l'espace qui isole les strophes et parmi le blanc du papier; significatif silence qu'il n'est moins beau de composer, que les vers. ${ }^{6}$
\end{abstract}

A passagem inclui uma frase sobre o canto. Ela vem logo após os «puissants calculs et subtils; mais on les ignore, eux mêmes se font, mystérieux exprès ${ }^{7}$. $\mathrm{O}$ ato de ignorar faz ressoar o "oubli" 8 , termo recorrente na obra mallarmeana. Pode-se pensar que as coisas que se passam no desapego, sem a intervenção do eu e de uma intencionalidade consciente, elas o fazem apenas porque já estão inscritas no inconsciente ${ }^{9}$. Igitur nos parece um conto-testemunha da inscrição de cálculos possantes: do encontro de uma fonte e do casamento entre a unidade e a propagação. Pelo canto, um jorro se propaga, e o que permite essa propagação talvez já faça parte da fonte.

É também em Igitur que vemos a gênese existencial, por assim dizer, ética e filosófica do espaço que isola as estrofes, espaço gerado a partir de um puro lugar, que reaparecerá no verso "Rien n'aura eu lieu que le lieu" ("Nada terá tido lugar senão o lugar"), de Un coup de dés ${ }^{10}$. O espaço é comparado na passagem ao alto com um "significatif silence". Em Igitur, lemos: " $C$ 'est le rêve pur d'un Minuit, en soi disparu [...] sinon que subsiste encore le silence d'une antique parole proférée par lui" 11 .

Veremos em breve a relação entre o lugar e a antiga palavra proferida pelo personagem Igitur. Antes de passar ao conto em si, mais algumas considerações introdutórias, para situá-lo na obra de Mallarmé ${ }^{12}$.

Em 1883, um ano após a passagem que lemos há pouco sobre a filosofia na poesia, Mallarmé escrevia, numa carta a Verlaine: “[...] je m'occupe de l'armature de mon oeuvre, qui est en prose. Nous avons été si en retard, du coté Pensée, que je n'ai point passé moins de dix années à édifier la mienne" 13 .

Repare-se o termo "armadura", também presente na passagem de 1882, de uma heráldica, disseminada na obra de nosso Mal ou bem, armé (que significa armado, em francês) e também presente em Igitur. O conto, de 1869-1870, parece nuclear aos dez anos da edificação do pensamento mallarmeano.

Talvez se possa religar o início dessa construção à grande ruptura experimentada por Mallarmé em 1866, enquanto escrevia Hérodiade: "Malheureusement, en creusant le vers à ce point, j'ai rencontré deux abîmes, qui me désespèrent. L'un est le Néant, auquel je suis arrivé sans connaître le Bouddhisme" ${ }^{14}$. 
Igitur, iniciado em 1869, parece ser o testemunho da descoberta do vazio, e de uma solução à crise de ao menos três anos que se lhe seguiu. Sabe-se que nesse período Mallarmé escreveu pouco, daí o importante Sonet en yx, e que ele desenvolveu certas leituras. Em notas concomitantes à elaboração de Igitur, que tinham por objetivo um projeto de tese nomeado De divinitate e que Marchal inclui no que chamou de Notes sur le langage ${ }^{15}$, lê-se:

En effet, le travailleur lit peu d'oeuvres faites. Le nôtre se retrempe assez volontiers dans les anciens auteurs de la renaissance ou du romantisme qui furent ses maîtres privilégiés. De plus, il aime 1'histoire - goût du passé. ${ }^{16}$

Além de à sua relação evidente com Hugo, Edgar Poe e Baudelaire, aos dois últimos sendo oferecida a tese que ele escreveria, o liame $\operatorname{com}^{17}$ o Romantismo parece remontar à filosofia do primeiro Romantismo alemão, lido também por aqueles escritores. É notável a semelhança entre o pensar do pensar descrito por Schlegel e a frase epistolar célebre de Mallarmé, de 1867: "ma pensée s'est pensée et je suis arrivé à une conception pure" 18.

A estética do fragmento preconizada por Schlegel e por Novalis, que afirmam esperar o Messias que saberia realizá-la em seus escritos ${ }^{19}$, parece incarnar-se em Mallarmé com o mesmo elo à reflexão infinita do pensamento que está no seio do idealismo alemão.

Mas que outras operações seriam necessárias para que isso pudesse se dar? É, em Mallarmé, a distância entre (1) estar encerrado no absoluto, "incapable de bouger"20, como ele o diz no conto e em cartas aos amigos, e (2) deixar que se desenvolva uma arquitetura complexa, do qual participa a imagem do corpo, sob o título de sombra, que permita o canto, ou seja, a criação fluida, infinita ${ }^{21}$.

Para a conexão com o Renascimento, além dos poemas desta época que encontramos copiados em seus cadernos de criança, ela poderia se fazer com o resgate de teorias do homem que escapam ao controle da Igreja e que paradoxalmente a alimentam na Idade Média.

Igitur possui traços importantes de um antigo Egito, dos rituais da cavalaria, de heráldica, alquimia e cabala que integram sejam os textos herméticos traduzidos ou desenvolvidos por Marsilio Ficino e Pico de la Mirandola no Renascimento, seja a maçonaria à qual pertencem os amigos felibres ${ }^{22}$ de Mallarmé em Avignon, onde Igitur foi escrito. A propósito de seus melhores amigos, para além de Avignon, Eugène Lefébure era um egiptólogo sério e renomado; Villiers de l'Isle Adam acabava de escrever Isis; Henri Cazalis escreveria Le livre du néant ${ }^{23}$, sobre um místico sufi. Mas o decisivo é que, em Mallarmé, essas informações se submetem a uma observação muito precisa dos movimentos de seu pensamento, em ligação com a linguagem. Por meio dos mitos de seus ancestrais, e da visão mesma de seus corpos, é o corpo do poeta que se objetiva, que se torna forma, mito mínimo. Ele integra "les quelques équations sommaires de toute fantaisie" ${ }^{24}$, frase de Divagations a propósito da Dança.

Procuraremos a seguir discernir alguns passos lógicos de Igitur em direção à possibilidade da Dança ou do Canto, palavra presente em escritos importantes de Mallarmé, como em seu último poema, "Au seul souci de voyager" ${ }^{25}$, que religa o canto à pedraria subterrânea, curiosa fonte da qual o pássaro se nutre a cada mergulho.

Num esquema de planificação nos manuscritos de Igitur, leem-se as seguintes partes do conto: 
1 - Le Minuit.

2 - L'escalier

3 - Le coup de dés.

4 - Le sommeil sur les cendres, après la bougie soufflée. ${ }^{26}$

Nos escritos herméticos do Renascimento e de depois, existia o costume de mudar a ordem das partes de um escrito para cifrar a leitura. Estudando Igitur, perguntamo-nos se este não era o caso, pois "Le Minuit" parece ser a última etapa da obra. Um indício é que ela termina assim: "Adieu, Nuit, que je fus, ton propre sépulcre, mais qui, l'ombre survivante, se métamorphosera en Éternité" 27.

Essa última frase evoca o objetivo do Livro egípcio dos mortos, cujo nome original é Livro para sair à luz. Um pouco como em Igitur, em que um livro se faz no túmulo, os mortos egípcios eram enterrrados com um texto-guia para atravessar o além e alcançar a eternidade, que não implicaria o fim de movimento, pois que o símbolo do deus da luz e da noite é a barca, que o morto deve estar pronto a adentrar. Mas talvez, também, o conto se inicie pelo final do drama porque é deste ponto de vista que ele começa a ser escrito, do ponto de vista do absoluto. "Puis - comme il aura parlé selon l'absolu" 28.

A primeira parte parece antes ser a segunda do esquema, aquela que é a mais elaborada, com uma dezena de esboços e numerosas rasuras. Ela se chamará: "Il quitte la chambre et se perd dans les escaliers (au lieu de descendre à cheval sur la rampe) ${ }^{29}$. Segue um levantamento de momentos lógicos do conto, em que simplificamos horrivelmente cada passagem ${ }^{30}$.

\section{A consciência da Noite.}

Sabe-se, pelos outros esboços e partes do conto, que o relógio parou à meia-noite, quando as portas do túmulo se fecharam sobre a sombra. Desde muito tempo na literatura, a sombra faz referência à pessoa humana e a seu corpo. Uma consciência entretanto subsiste à morte do personagem, mas é a consciência da Noite. Como se numa lembrança, ela percebe o movimento do pêndulo que expira em si e se extingue (dupla alusão: ao coração e ao relógio que param). Então a Noite sabe que ela o traz ainda (o ir e vir do "pêndulo", de mesma raiz etimológica que o "pensamento", é comparável ao movimento deste último, e o pêndulo também sugere um sujeito singular) e conclui que é dela que provinha o barulho das portas do sepulcro, tombando em seu passado.

Toda realidade é portanto contida neste vasto sujeito - a Noite - , sem forma, mas que se percebe consciente. Ela desempenha o papel de absoluto, que ultrapassa a morte e a consciência egoica do sujeito.

\section{O pensar do pensar e a cessação: estabelecimento de um Lugar de pensamento, uma câmera (chambre), um intervalo.}

Se o pêndulo parou, uma moção de pensamento ${ }^{31}$ entretanto dura, "comme si la chûte totale qui avait été le choc unique des portes du tombeau, n'en étouffait pas l'hôte sans retour" 32 . Quase imperceptivelmente, passa-se aqui ao ponto de vista do hóspede singular, uma espécie de pensar da Noite e da sombra (hóspede do absoluto) se confundindo. Em seguida, 
se présente une vision de la chute interrompue de panneaux, comme si c'était soimême, qui, doué du mouvement suspendu, le retournât sur soi en la spirale vertigineuse conséquente; et elle devait être indéfiniment fuyante, si une oppression progressive [...] n'en eût impliqué l'évasion certaine en un intervalle, la cessation ${ }^{33}$.

Note-se que se trata do si, através das formas sutis do túmulo do corpo. A cessação deriva deste movimento do que se poderia compreender como uma reflexão do pensamento, até que um lugar objetivo mental se estabeleça. A palavra "cessação", equivalendo no universo budista (divulgado por Schopenhauer e por estudos do século XIX) ao desapego de si e à iluminação, prende-se aqui a um intervalo, em outro lugar do conto chamado de "chambre de temps" ${ }^{34}$. O que sugeria mais acima um ponto ("Le Minuit" ${ }^{35}$ ) se transforma em um intervalo de um ponto a outro, um quarto. A consciência é metaforizada por esse quarto vazio no qual os painéis laterais se refletem. Eles sugerem as delimitações mentais e sutis de um espaço interior de consciência.

Um dos sentidos de "panneau"36 é "face de pedra talhada" ${ }^{37}$. O intervalo é delimitado pelos painéis da pedra sepulcral de si, apenas perceptíveis porque a atenção da sombra não está presa a seu corpo - o amálgama rompido pelo vazio do choque das portas do sepulcro em seu enterro ou desaparição como objeto de si. Desapegada de si, a atenção se volta para a marcha do espírito e suas formas imediatas.

Poderíamos pensar que uma outra pedra é um objeto que se formará pouco a pouco. Ela nasce do túmulo de si, pois os painéis que a formam se confundem com as portas do sepulcro. Estamos aqui, talvez, frente à formação da pedra filosofal alquímica, que Mallarmé considera segundo as operações do pensamento e da formação de um recinto interior de consciência. "La notion d'un objet, échappant, qui fait défaut", de La Musique et les Lettres ${ }^{38}$. A palavra "noção" aparece já em Igitur.

\section{O desdobramento fotogramático do personagem. Seu nasce-morre.}

Uma ponderação tem vez: o ofegar que precedera a cessação era o trabalho das antigas e nobres gerações da sombra. Segue o longo trecho em francês. Pela continuação do conto, sabemos que cada sombra que se apresenta segura numa mão uma lâmpada e noutra um livro, descritos aqui por meio de metáforas doadoras de novos sentidos.

Car, pour le halètement qui avait frôlé cet endroit, ce n'était pas quelque doute dernier
de soi, qui remuait ses ailes par hasard en passant, mais le frottement familier et
continu d'un âge supérieur, dont maint et maint génie fut soigneux de recueillir toute
sa poussière séculaire en son sépulcre pour se mirer en un soi propre, et que nul
soupçon (n'en remontât) le fil arachnéen pour que l'ombre dernière se mirât en son
propre soi, et se reconnût en la foule de ses apparitions comprises à l'étoile nacrée de
leur nébuleuse science tenue d'une main, et à l'étincelle d'or du fermoir héraldique de
leur volume, dans l'autre; du volume de leurs nuits; telles, à présent, se voyant pour
qu'elle se voie, elle, pure, l'Ombre, ayant sa dernière forme qu'elle foule, derrière
elle, couchée et étendue, et puis, devant elle, en un puits, l'étendue de couches
d'ombre, rendue à la nuit pure, de toutes ses nuits pareilles apparues, des couches à
jamais séparées d'elles et que sans doute elles ne connurent pas - qui n'est, je le
sais, que le prolongement absurde du bruit de la fermeture de la porte sépulcrale dont
l'entrée de ce puits rappelle la porte.

A sucessão das sombras, a lâmpada ou tocha, e o fecho heráldico do livro que cada uma segura evocam uma espécie de procissão surrealista de cavaleiros. Ela tanto parece aludir a 
uma linhagem de "buscadores" a que o personagem pertenceria, quanto, menos que a outras vidas (a metempsicose de que a antiguidade falava) desse mesmo personagem, ao funcionamento da consciência: a procissão pode então ser compreendida como a das próprias aparições do narrador-personagem de um instante a outro, em sua constante criação e morte, à qual correspondem os intervalos de consciência.

O narrador se explicita personagem precisamente, e pela primeira vez desde o início de "Il quitte la chambre", na antepenúltima linha do trecho acima — "je le sais" 40 —, mas três linhas antes ele já se autoindicava por "en ce puits" ${ }^{41}$, como se nele estivesse. A expressão volta no finalzinho do trecho: a entrada "de ce puits" 42 lembra a porta. A narração depois disso mesclará a primeira e a terceira pessoa, até ficar só na primeira.

\title{
4. A consciência de si.
}

Um Lugar continua a se mostrar, como deveria ser "l'intervalle attendu, ayant, en effet, pour parois latérales l'opposition double des panneaux, et pour vis-a-vis, devant et derrière l'ouverture de doute nul, répercutée par le prolongement du bruit des panneaux [...]" ${ }^{43}$, abertura ("ouverture") correspondendo ao passado e ao futuro.

Conforme vimos, é como se os painéis se reabrissem para formar as paredes insubstanciais de um recinto de consciência. Mas a cada vez que uma sombra cai no poço, os painéis se fecham, para se reerguer no intervalo seguinte."[...] C'était la conscience de soi (à laquelle l'absurde même devait servir de lieu) — (sa réussite)" ${ }^{44}$. Mesmo se toda essa alucinação evoca o absurdo, este se explicará melhor na parte seguinte do conto.

\section{A reflexão da luz e do volume nas paredes laterais. A emergência da primeira pessoa.}

O fólio anterior foi cortado, de modo que mal dá para deduzir hipoteticamente a cena aqui em curso. A sombra (supomos) "se apresenta igualmente numa e noutra face das paredes luzentes e seculares ${ }^{45}$ guardando dela apenas, com uma mão, a clareza opalina de sua ciência e, com a outra, seu volume, o volume de suas noites agora fechado". Uma hipótese é que haja um propósito em isolar da sombra apenas a luz e o volume, e que isso também possa corresponder à última figura a que o texto se referirá mais adiante. Vejamos o trecho todo:

\begin{abstract}
se présente également dans l'une et dans l'autre face des parois luisantes et séculaires ne gardant d'elle que d'une main la clarté opaline de sa science et de l'autre son volume, le volume de ses nuits maintenant fermé du passé et de l'avenir que parvenue au pinacle de moi, 1'ombre pure domine parfaitement, et finis, hors d'eux. Tandis que devant et derrière se prolonge le mensonge exploré de l'infini, ténèbres de toutes mes apparitions réunies, à présent que le temps a cessé et ne les divise plus, retombées en un lourd somme, massif, (lors du bruit d'abord entendu), dans le vide duquel j'entends les pulsations de mon propre coeur. ${ }^{46}$
\end{abstract}

O fechamento do volume liga-se à extinção do tempo e à objetivação do eu numa forma - a sombra e o próprio livro. “(...) chegada ao pináculo de mim, a sombra pura domina”: temse aí congregado o contraste entre a primeira pessoa (implícita em "[no] pináculo de mim") e a terceira ("a sombra pura domina"). É aí, na objetivação de si mesmo numa forma, enquanto o sujeito está no vazio, no poço, que nasce o discurso em primeira pessoa. É o personagem do 
sujeito da enunciação que surge, mito mínimo, em pleno presente. O sujeito mesmo, entretanto (como o mestre que desceu ao Styx, no Sonnet en yx), está abismado em relação à sombra, ele no fundo do poço, onde todas as aparições vêm cair. A divisão entre os dois planos - baixo e alto - lembra a imagem do gênesis de "Le Minuit": "et que de l'infini se séparent et les constellations et la mer, demeurées, en l'extériorité, de réciproques néants, pour en laisser l'essence, à l'heure unie, faire le présent absolu des choses." 47

Repare-se ainda, na cena de "Il quitte la chambre", que dois fechamentos são evocados e se articulam para formar o presente: o do livro (fechando a sucessão como que horizontal das aparições da sombra pelo tempo) e o do sepulcro (separando verticalmente o sujeito e sua sombra).

\section{Clareza demais.}

A sombra - no poço ou vazio do qual ela ouve as pulsações de seu próprio coração - se incomoda com a lucidez e a certeza de si: "Je n'aime pas ce bruit: cette perfection de ma certitude me gêne: tout est trop clair, la clarté montre le désir d'une évasion; tout est trop luisant, j'aimerais rentrer en mon Ombre incréée et antérieure (...)" ${ }^{48}$. A sombra é levada a deixar este quarto de consciência, à sua dissolução, a um retorno ao Caos. A consciência de si figura agora como uma prisão, espaço no alto, fora do corpo, espécie de túmulo aéreo, e tratarse-á de encontrar os meios para a propagação deste intervalo. Nas notas do conto, lê-se: "Telle est la marche inverse de la notion dont il n'a pas connu l'ascension, étant, adolescent, arrivé à l'Absolu, incapable de bouger" ${ }^{49}$.

Como a saída do quarto se torna possível? Como não ser paralisado? A questão subjacente é: como a unidade se transforma em devir? Como a sombra atual poderá morrer para dar vez ao próximo intervalo? Como nascerá a possibilidade do Canto (Chant, em francês), palavra que percorre os escritos mallarmeanos? É também a troca da visão pela palavra. Mas antes que isso seja possível, outros movimentos lógicos têm vez.

\section{Busca de saída por uma das aberturas do quarto, repetição do processo de meditação (espiral), até chegar a um personagem.}

Pegar a abertura do passado ou do futuro dá no mesmo, no mesmo-diverso, já que se trata sempre de escansões de um personagem ${ }^{50}$, manifestadas num murmúrio-roçar: "En effet, la première venue ressemble à la spirale precedente: même bruit scandé, - et même frolement" ${ }^{51}$. A pergunta ou o desejo voltam-se, de novo, da fenomenologia do pensamento para o sujeito que lhe é suporte: "Ce scandement n'était-il pas le bruit du progrès de mon personnage qui maintenant le continue dans la spirale, et ce frôlement, le frôlement incertain de sa dualité?" 52.

\section{6. "Decapitação" do nobre personagem, identificação da sombra-narrador em primeira pessoa com ele. Constituição de uma reta vertical por onde a "noção" sobe e desce.}


Aqui, neste final de "Il quitte la chambre", o narrador personagem tem a visão de um busto de veludo de alguém de "uma raça superior", como se de um ancestral com gola alta de renda em estilo shakesperiano ("fraise arachnéenne"). Sobre a gola e separada deste personagem, a última figura do narrador. A imagem sugere uma decapitação, tema recorrente em Mallarmé, e aqui, pelo contexto heráldico, ela nos remete ao ritual cavaleiresco da "collée", da "accolade", do "adoubement", cerimônia de sagração do cavaleiro por meio de um toque da espada no seu ombro ou pescoço, simbolizando uma decapitação: o agora cavaleiro troca a sua cabeça pela do Cristo, seu personagem-guia. No conto, trata-se da última figura do narrador ("ma dernière figure") - o reino é o da sucessão de manifestações do homem-tipo (ao qual em outro escrito é comparado o Cristo) $)^{53}$. A última figura alude tanto a um novo desdobramento de si, naquela procissão de sombras do personagem, quanto talvez possa remeter ao volume e à clareza (o livro e a lâmpada, um pouco antes no texto). Num esboço anterior, "Autre ébauche" ${ }^{54}$, essa figura é um clarão ${ }^{55}$. O Messias é aquele que vem - ele pode ser visto nesta vinda, de um intervalo a outro, de si mesmo feito outro, manifesto tanto numa imagem corpórea quanto não corpórea, ou de uma corporalidade diversa (o clarão).

Uma identificação do narrador-personagem com este corpo objetivo do personagem decapitado permite que o primeiro se esqueça de si: "aussi, maintenant que sa dualité est jamais [ou "à jamais" 56] séparée, et que je n'ouïs même plus à travers lui le bruit de son progrès, je vais m'oublier à travers lui, et me dissoudre en moi." 57 Repare-se no termo "oublier", ao qual nos referimos no início.

Pode-se ler este trecho assim: agora que, pelo símbolo da decapitação, a fratura do sujeito se mostrou e se fixou numa imagem, posso identificar-me a ela sem problema, porque ela traz o sinal de uma busca do que ela não é. Não serei capturado por uma totalidade imaginária ilusória. E nem, tampouco, por um quarto fora do corpo $^{58}$. Pois a objetivação de uma linha vertical correspondente ao corpo do personagem-estátua permite o deslocamento do quarto do tempo num eixo vertical e estranhado em relação ao sujeito. Ela descola o sujeito da visão do quarto, pois dá-lhe uma linha alternativa. A imagem vertical do corpo é suporte do deslocamento do quarto, transformado nos objetos que nele foram vistos: um livro e uma lâmpada, seja volume e luz, que o personagem traz pela escada quando ele pode agora deixar o quarto e descer. Lembramos aqui uma sigla latina dos escritos alquímicos: V.I.T.R.I.O.L.U.M. - "Visita Interiora Terrae Rectificando Invenies Occultum Lapidem Veram Medicinam" (Visita o Interior da Terra, e Retificando Encontrarás a Pedra Escondida, Universal Medicina [ou remédio]). O que resta a ser retificado, que fará a ponte entre o Quarto e o Canto?

Até aqui, tratava-se de uma meditação ligada ao pensamento e à visão, inda que acoplados aos signos verbais (por meio dos quais o personagem sonda os caminhos, perguntase, etc.). Na parte seguinte do conto, "Le coup de dés" ${ }^{59}$, uma Palavra específica será proferida. Uma palavra consagrará o pacto do sujeito com o Outro que o ultrapassa e que já foi conhecido enquanto consciência da Noite.

Parece haver na descida uma metamorfose de espaços retangulares: o quarto, o livro e logo os dados, que surgirão do nada na cena seguinte. Na heráldica, a descida dos dados é um símbolo da descida do lugar edênico à terra.

\section{Descida no subterrâneo e pacto com o Outro por meio de seu Nome: a predição (ou o Nome) é proferida, os dados são lançados, o sujeito se nadifica.}


Dos muitos ensaios narrativos de "Le coup de dés", no manuscrito, damos por ora esta sequência costurada a partir de vários fragmentos: o personagem, descido com o livro e a lâmpada, abre o livro. "Il profère la prédiction, dont il se moque au fond. Il y a eu folie" 60 (Oc1, p. 841). Ele joga os dados, o lance se cumpre, 12. Bebe uma gota de vazio e deita-se no túmulo dos ancestrais.

Este personagem do subterrâneo (do poço) parece então ser aquele que era pisado pela sombra seguinte a ele na "procissão" de sombras; o nobre "decapitado" talvez. Entre uma sombra e a outra um ato, um lance de dados, um novo mergulho onde um pacto ao Outro é refeito.

A predição proferida evoca a "antiga palavra" de "Le Minuit": "le silence d'une antique parole proférée par lui" ${ }^{61}$ (Oc1, p.484, grifo nosso). Que pode ser ela? Hipótese: o nome do Outro, que ultrapassa a sombra e se apresenta como a Noite em "Il quitte la chambre" 62.

Os dados, "Hazard" em árabe (daí o uso do" z" na palavra francesa normalmente grafada com "s" 63), materializam o lugar vazio de consciência ${ }^{64}$, feito "pedra", o que já era sugerido, em "Il quitte la chambre", pela palavra "panneau" 65 , da qual um dos sentidos é, conforme vimos, "face de pedra talhada". É como se aquele espaço de consciência experimentado no quarto adquirisse uma existência objetiva. Na heráldica e na alquimia em geral, o dado é um símbolo da pedra filosofal ${ }^{66}$, que em Mallarmé talvez se aparente à "Noção" (Notion), formando-se na primeira parte de "Il quitte la chambre", começando a sair do espaço mental interno na identificação do protagonista com a imagem do nobre personagem que a carrega enquanto livro/volume, e precisando ligar-se a uma palavra para objetivar-se de vez e propagar-se quando convocada.

Em "Il profère la prédiction", há um jogo notável entre PRO, sinal de futuro, e PRE, sinal de passado. "Profèrer" quer dizer falar e, etimologicamente, levar (latim "fero") adiante ("pro"). Levar, lançar o quê? A predição, com dois sentidos, neste contexto.

A predição é o que se diz antes ("pre”), antes do acontecimento pressupõe-se. A predição é o que se diz que vai ocorrer. Nesse caso, a predição ratifica o sentido de "Pro-ferir". Uma sugestão de seu poder performático é inevitável: a de que uma palavra constele no espírito o que ela diz.

O que aconteceu antes da dicção (pré-dicção). Aqui, a referência pode ser à parte anterior do conto, "Il quitte la chambre", em que se evidenciou um intervalo (de plena consciência). Proferir a predição equivale a lançar adiante um novo intervalo. Mas isso só se faz pelo chamado não de um intervalo diretamente, porém do sujeito implícito não só nesse intervalo, mas no que está além dele e poderá deixá-lo.

E faz-se também com a morte do sujeito invocante, de seu corpo, com a gota de vazio bebida por ele antes de se deitar no túmulo de seus ancestrais.

"Il y a eu folie" 67: ato de Loucura, perder a cabeça, consagrar a cabeça do Outro. Neste sentido, a Loucura é amor, o chamado do outro. O sujeito que profere a palavra reconhece o Outro como sua origem e seu destino. Ele se troca pelo absoluto, que se manifestará depois como intervalo.

Quais são as evidências no conto de que a "frase" ou a "palavra" proferidas no lançar dos dados concernem ao nome do Outro?

Uma das pistas são os rituais ligados aos símbolos heráldicos do conto, sejam rituais 
alquímicos ou maçons. Pois, de acordo com a semiologia heráldica, os dados são também uma das variantes do tetragrama sagrado que nomeia Deus, um Deus ele mesmo fraturado no seu devir (que se auto-cria e convoca, conforme interpretações que se fazem do tetragrama ${ }^{68}$ ). No mito maçônico, esta "antiga palavra" 69, o tetragrama, era a palavra de passe dos mestres, e havia apenas três deles, a palavra só podendo ser pronunciada por um na presença dos outros dois. Mas quando um dos três mestres que a conheciam foi assassinado (Hiram), ela teve que ser substituída por uma outra palavra ${ }^{70}$, preferencialmente iniciada por M. Em Igitur, o absoluto é simbolizado por "Minuit" 71, Meia-Noite, palavra masculina em francês, que nomeia o primeiro "ato" do conto, e complementar ao feminino Noite, naquela contida (ou daquela saída, como uma costela), protagonista do segundo ato do conto-peça de teatro. Mas "Elbehnon" talvez o indique mais secretamente, como veremos em breve.

Retornemos à frase de Igitur: "Il profère la prédiction, dont il se moque au fond. Il y a eu folie" 72 (Oc1, p. 841). A predição prevê o absoluto (12, número máximo quando se lançam dois dados). Predição da qual o personagem caçoa ao fundo: no fundo nada, o corte entre os dois dados, entre o sujeito e seu absoluto. Absoluto que depende de um ato performativo. Ele não existe a priori, ele é constantemente performatizado pelo Verbo. Ele é talvez o Verbo (tema das notas em vista de um projeto da tese "De divinitate" concomitantes a Igitur), compreendido para além do som e da palavra formal, inscrição atualizada de um ato (ou convite) de pensamento, como surge em "Le Minuit", a primeira parte do conto e a última da Obra, numa passagem que veremos logo mais $^{73}$.

É preciso dois dados para fazer o número 12, signo de Meia-Noite, de absoluto. Dois dados querem talvez dizer a fratura necessária de si. A fratura aqui sincrônica, como o corpo cortado da cabeça do ancestral (e de São João Batista em Hérodiade), liga-se à segmentação diacrônica, como na sucessão de intervalos, e como na lógica da rima, de um encadeamento de versos no coração do canto:

\begin{abstract}
Voilà, constatation à quoi je glisse, comment, dans notre langue, les vers ne vont que par deux ou à plusieurs, en raison de leur accord final, soit la loi mystérieuse de la Rime, qui se révèle avec la fonction de gardienne et d'empêcher qu'entre tous, un usurpe, ou ne demeure péremptoirement: en quelle pensée fabriqué celui-là! peu m'importe, attendu que sa matière discutable aussitôt, gratuite, ne produirait de preuve à se tenir dans un équilibre momentané et double à la façon du vol, identité de deux fragments constitutifs remémorée extérieurement par une parité dans la consonance. ${ }^{74}$
\end{abstract}

7. Ao final da segunda parte de Igitur, "Le coup de dés", o personagem bebia uma gota de nada e deitava-se no túmulo de seus ancestrais. A partir desse ponto podemos pensar em duas ramificações do conto, talvez concomitantes em diferentes níveis.

7.1. Em um de seus ramos, o sujeito se encontra de novo no quarto, por meio da Noite um novo intervalo se produz, nessa espiral inerente ao progresso infinito da criação, que pressupõe a renovação do pacto com o Outro e sua pedra-pensamento, exatamente como, em $\mathrm{Au}$ seul souci de voyager ${ }^{75}$, o pássaro em cada mergulho periódico "vê" a pedraria ("nuit, désespoir et pierrerie"76), "recife" no poema Salut ("solitude, récif, étoile") 77.

Em outras, mais detalhadoras palavras, depois que o Outro é chamado, a consciência (da Noite) dialogiza-se, autorreflete-se por meio dos dois painéis tumulares de seu hóspede 
singular até chegar a um espaço individualizado (o quarto, o intervalo): que existe para um sujeito enterrado. É esse sujeito que, manifestando-se na forma do nobre personagem simbolicamente decapitado, poderá escapar ao intervalo, voltando ao Caos, onde convidará de novo o absoluto, tendo sua forma corpórea dissolvida pela gota de nada. Esse absoluto logo se transmutará em novo intervalo de consciência. Desse modo, o intervalo propaga-se.

7.2. Em outro de seus ramos, encontramo-nos na primeira parte do conto, o sujeito liberto em um quarto mobiliado. "Certainement subsiste une présence de Minuit" ${ }^{78}$, ou então: "C'est le rêve pur d'un Minuit, en soi disparu [...], sinon que subsiste encore le silence d'une antique parole proférée par lui." (Oc1, 484) ${ }^{79}$

Quando esta parte termina por "Adieu, nuit, que je fus, ton propre sépulcre, mais qui, l'ombre survivante, se métamorphosera en Eternité" 80 (repare-se aqui o "eu" consistente transmitido pelo segmento independentizado pela vírgula em "que eu fui" equivalendo ao sepulcro da Noite; e sua substituição pela "sombra", "imagem" corpórea filha da Noite), podese entender também que, se o sujeito pode aceder à luz, a seu quarto onde seus móveis (de que móveis se trata? Impossível não pensar no sentido heráldico desta palavra, a designar as formas significantes desenhadas no brasão pessoal que capacita o cavaleiro para o combate) são visíveis e uma face também, o encontro com a Noite é reposto assintoticamente, como o El (de Elbehnon, veremos daqui a pouco) está sempre além e mais longe. A Noite, com efeito, retornará a cada mergulho, a cada morte. Esta morte e a procissão de sombras onde ela se implica, cada uma sendo pisada pela seguinte, está implícita em: "[...] l'infini est enfin fixé. sauf que mouvement (personnel) rendu à l'infini" 81 (Oc1, p. 477).

Nas fundações do canto temos um chamado ao Outro seguido da morte ou dissolução de si; Lugar, Noção ou pedra; ressurreição como sombra objetivada ou personagem. Renovados pela eternidade. Esses são movimentos necessários à arqueologia viva de toda linguagem.

Em "Le coup de dés", a palavra que convoca o absoluto absolve a antiga ideia de absoluto, como de algo que existisse por si só, intrinsecamente, mas fixa a possibilidade de sua experiência ("l'infini est enfin fixé"), ao descobrir que ele se cria pela convocação, o corpo do sujeito que profere a palavra dissolvendo-se para que apenas a noite que ela instaura sobreviva. Voltamos assim ao momento em que o "coup de dés" equivale ao fechamento da porta do sepulcro, a sombra esvaindo-se na obscuridade, em "Il quitte la chambre".

A dialogização da Noite, do sujeito absoluto ("antique idée") fracionando-se em diferentes funções do Teatro ${ }^{82}$, bem como o paradoxo (contido na forma arcaica e polissêmica "absolut") de abolir e de tornar absoluto o Minuit, isto é, o Absoluto, podem ser lidos nessa condensada passagem de "Le Minuit", que prefigura o enredo todo do conto:

Depuis longtemps morte, une antique idée se mire telle à [la] clarté de la chimère en laquelle a agonisé son rêve [et] se reconnaît à l'immémorial geste vacant avec lequel elle s'invite, pour terminer l'antagonisme de ce songe pôlaire, à se rendre, avec et la clarté chimérique et le texte refermé, au Chaos de l'ombre avorté et de la parole qui absolut Minuit (Oc1, p. 484). ${ }^{83}$

Se a reiteração da morte/ressurreição faz parte da vida e pode-se supor o caráter circular entre a segunda ("Il quitte la chambre") e a terceira parte do conto ("Le coup de dés") mesmo que na própria segunda parte o personagem diga que, com a repetição, ele perca o 
medo e passe a conhecer o processo, e mesmo que a ambiguidade remanescente no coração que batia (quando tudo era claro demais, mas o sujeito ainda estava fechado em si) seja ultrapassada pela fixação de um personagem com o qual o sujeito se identifica (o conto seria então circular apenas em parte; a imagem de espiral cabendo-lhe melhor ${ }^{84}$ ) —, por outro lado, uma outra "terra", fora do corpo físico e das percepções dos objetos à volta (cf. "quelque suprême moule n'ayant pas lieu en tant que d'aucun objet qui existe [...]". Oc2, p. $200{ }^{85}$ ), se estabelece, e isso equivale ao espaço descrito em "Le Minuit", espécie de quarto em que os opostos entram em conjunção, como a imobilidade e a movência — "cependant que s'immobilise, (dans une mouvante limite,) la place antérieure de la chute de l'heure en un calme narcotique de moi pur longtemps rêvé" ${ }^{86}$.

\section{ELBEHNON}

A fragmentação das palavras que aparecerá em Les mots anglais ${ }^{87}$, de 1874 , com os sentidos e sugestões de cada fonema e letra, apresenta-se já em Igitur no que Marchal chamou de Bribes: des cendres/ descendre; étoile/toile[88], etc. Mas isso é só uma manifestação do corte salvador do pesçoco do sujeito. É o valor do corte e do fragmento em Igitur que nos conduziu a explorar os componentes significantes de Elbehnon (no título consagrado pela tradição editorial do conto: Igitur ou la Folie d'Elbehnon), mas de um modo um pouco diferente de como isso foi feito antes. Robert Greer Cohn (1981, p. 20) havia criticado a visão de Rolland de Renéville (1938, p. 90), para o qual Elbehnon seria composto de duas palavras hebraicas, El behnon, significando "o filho dos Elohim" (Elohim equivaleria às "potências criadoras emanadas de Jeová"), mas os apontamentos de Fabre de Olivet nos conduziram à hipótese de uma outra composição hebraica do termo mallarmeano. Elbehnon traria, de acordo com ela, uma súmula da estrutura subjetiva-objetiva desdobrada no conto.

Fabre de Olivet (1767-1825) foi um dos precursores dos felibres, na valorisação da língua d'Oc. Nascido a uns $100 \mathrm{~km}$. de Avignon, teve ainda em comum com os felibres amigos de Mallarmé a temática da maçonaria e do hebraísmo que caracteriza ao menos seu mito de origem (a legenda de Hiram e da antiga palavra hebraica). No livro La langue hébraïque restituée et le véritable sens des mots hébreux - cuja "dissertação introdutória sobre a origem da Palavra" evoca as preocupações de Mallarmé explicitadas em Notes sur le langage, concomitantes a Igitur, a filosofia nelas se aliando a um interesse pela linguística comparada de línguas antigas - encontra-se uma listagem de raízes linguísticas hebraicas, com os sentidos que elas sugerem. Topamos com coisas interessantes quando examinamos os componentes de Elbehnon à luz da tabela de Olivet. Antes de comentá-las, cumpre notar que este autor inserese na forte tradição da cabala provençal. Junto com a Espanha e a Palestina, a Provença foi o berço da cabala. É nela que foi produzido o Bahir, um dos três livros considerados como os mais importantes desta tradição da mística judaica que deu origem à cabala cristã, de considerável repercussão no final da Idade Média e no Renascimento. O Bahir por sua vez baseia-se em parte num anterior a ele, o Sêfer Ietsirá, que fala dos números e das letras. $\mathrm{Na}$ mesma época em que o Bahir foi produzido, o hispânico, fundador da cabala profética no século XIII, Abraham Abouláfia, escrevia, também baseado no Sêfer Ietsiráa ${ }^{89}$, sobre o sentido das letras hebraicas e de suas combinações, o Tserouf. Fabre de Olivet inscreve-se portanto na 
tradição do Tserouf, que tinha como uma de suas metas abrir a escuta à plurisignificação e aos níveis "sod" (secretos, em hebraico) da linguagem, que dizem respeito à estrutura da criação.

A composição de El- beh - non sugere uma gramática compatível com o teatro interior de Igitur. Quando decompomos Elbehnon em sílabas hebraicas, temos os elementos mínimos do processo de criação.

Em linhas gerais, "El" (transliteração de Aleph, Lamed, Al; mas relacionável também com Hel/El) é o que está além ("au-delà", como no verso de Un coup de dés: zaussi loin qu'un endroit fusionne avec au-delà" ${ }^{90}$ ), o Outro. Sobre El enquanto Alef, Lamed:

Esta raiz se eleva sobre todos os signos reunidos da potência e do movimento extensivo. As ideias que ela desenvolve são as de elevação, da força, da potência, da extensão/duração [étendue]. Os hebreus e os árabes tiraram daí o nome de Deus.

No estilo hieroglífico, é o símbolo da força excêntrica. Num sentido restrito, é tudo que tende a uma meta, representado pelas relações designativas ou adverbiais a, em direção a [vers], para, por, contra, sobre, sob, etc. [...]

Em seu excesso de extensão, é tudo que desvanece [s'évanouit], tudo que é vão, tudo que se exprime pela relações adverbiais não, nada, nenhum/nulo, [non, point, nul, rien] etc. (D'Olivet, 1815, p.12)

Mas o El (de Elbehnon) também poderia se ligar ao HEL/ EL, e as explicações aqui são igualmente curiosas. Seguem apenas algumas, ligadas à simbologia da vida e de movimento excêntrico, de afastamento: "[...] no sentido figurado, ela [a raiz HEL/EL] caracteriza um sentimento de hilaridade e de felicidade, uma exaltação; no sentido próprio, ela exprime tudo que é afastado, ulterior, posto além [placé au-delà]". Ou ainda: "Tudo que se exalta, resplandece, se eleva, se glorifica", "Tudo que atinge o alvo desejado, que recupera ou dá saúde, que chega ou conduz à salvação" ${ }^{91}$. Tenha-se em mente que em Igitur a "hora" é alcançada, ainda que um intervalo dê lugar a outro intervalo.

É interessante reler Mallarmé com essas informações, especialmente o paradoxo entre o afirmativo e o negativo contido na raiz do mais alto (El), e a oscilação entre o sentido de "alvo" e o de "ir em direção a", "vers" - termo (e meio) tão presente na obra mallarmeana. Menos, talvez, que o uso de "nul" e outras palavras negativas (por exemplo, "joyau nul de rêverie", "aux yeux nuls pareils au miroir" ${ }^{92}$ ).

Quanto ao Aleph, a que corresponde usualmente a primeira letra hebraica da transcrição El, ela é uma consoante muda, equivalente ao número 1. O Aleph "é a única letra que não produz som por si mesma numa palavra - e ainda assim dela surge o alfabeto inteiro de sons e infinitos significados. Os sábios consideram o Aleph como significando que tudo que cada um de nós realiza [...] primeiro emana do repouso e do silêncio. [...]É a força primária da Criação que existe antes que qualquer forma possa ser visualizada, pois a Bíblia mesma começa com a segunda letra, Beit, não a primeira". ${ }^{93}$ O Alef de El, em Elbehnon, aludiria portanto a uma força, a uma letra inicialmente não vocal, de onde nasce todo som - o verbo mudo que a palavra proferida evoca, ao preço da desaparição da sombra.

$\mathrm{BeH}$ - BH (não importa que haja uma vogal entre B e H) é uma "raiz onomatopaica, que pinta o barulho que faz uma coisa ao se abrir, e que, representando-a escancarada, oferece à imaginação a ideia de um abismo [... ]" 94 .

BehN - BN: apesar de haver entre B e N, o H (podendo ser lido como a vogal "e" 
aspirada ou não ${ }^{95}$ ), tem-se a sugestão de Ben, filho. Ademais, uma das aparições da palavra toda em Igitur é "Elbenon" (Oc1, p. 474), sem o h.

[...] esta raiz desenvolverá a ideia de uma extensão geradora, de uma produção análoga ao ser produtor, de uma emanação [...] ela será o símbolo de toda produção ativa, indo de potência em ato, de toda manifestação do ato gerador, do eu [moi].

Num sentido figurado, é uma emanação inteligível, ou sensível; num sentido próprio, é um filho, uma formação, uma corporificação, uma construção. (D’Olivet, 1815, p. 20, "Racines Hébraiques")

NoN - a raiz NN, podendo conter uma vogal no meio, sugere a unidade que se propaga. Mesmo o $\mathrm{N}$ sozinho "representa o filho do homem, todo ser produzido e particular[...]. Colocado no final da palavra, torna-se o sinal aumentativo, e dá ao ser toda extensão da qual ele é individualmente suscetível." (D’Olivet, 1815, p. 80). Sobre a raiz NN: o signo da existência individual e produzida, tendo-se reunido a si mesmo como signo aumentativo, constitui uma raiz cujo emprego é caracterizar a continuidade da existência pela geração. É uma produção nova que emana de uma produção mais antiga para formar uma cadeia de indivíduos da mesma espécie (ibid., p. 87).

"Non" evoca "la notion d'un objet, échappant, qui fait défaut" ( "a noção de um objeto, escapante, que faz falta"). A importante palavra mallarmeana "Notion" contém duas vezes Non, no começo e no final ("no" inicial + "n" final; "no" de trás para frente + "n" inicial), como uma reflexão de espelhos gerando o infinito.

O elo disso com Igitur (e a cena da procissão de cavaleiros pelo tempo é apenas uma das evidências deste elo) é notável. Sobre NoN (de Elbehnon): "tudo que se propaga abundantemente, tudo que se estende e pulula, num sentido restrito, a espécie dos peixes ${ }^{96 "}$ (D’Olivet, 1815, p. 87; 339). A última fase da obra alquímica é a da propagação do ouro.

Em Igitur ou la Folie d'Elbehnon, talvez o nome "Elbehnon" congregue sinteticamente o Outro e os cálculos sutis da criação renovada. Tem-se o "au-delà" ou o Minuit em EL; o abismo/vazio súbito e até o barulho (do fechamento das portas do sepulcro, mas de abertura de uma outra dimensão) em BH; o filho, hóspede da Noite e personagem em BeN, ou BehN, em elo com El, no lançamento de dados e na predição; a noção (notion) reapresentando-se ao infinito em NoN. A propagação do ouro ("or") é aqui, no conto, a propagação da hora ("heure"). E de cada fragmento de palavra, evidente nas explorações com as letras ao longo da narrativa: "la lettre - l'équivalent de la Fiction" 97 . A propagação é também, nos bastidores da arte (tema da passagem mallarmeana no início deste texto), a do próprio pacto instituidor do sujeito e do além dele, a cada lance de dados. A "sombra", que não deixa de ser "filho", tem uma função operativa nessa possibilidade de desdobramento.

Mallarmé diz, numa carta, ter escavado (do verbo francês "creuser") o verso quando ele escrevia Hérodiade. A conjunção entre a palavra antiga, que faz pacto com o Outro, e a imanência; entre o acaso-pedra-puro-lugar e o acaso de cada vestido ou palavra, esta conjunção é formulada em inúmeras passagens da obra. Os alemães do primeiro romantismo já diziam que a reflexão do pensamento é a dimensão profunda de toda arte e de toda crítica. A esta reflexão, em Mallarmé se acrescentou a loucura ou o chamado do Outro (mas isso talvez já estivesse no Schlegel das Lições), incorporado na «matéria» sensível e primeira dos Dados ${ }^{98}$; e também se acrescentou a objetivação necessária do corpo humano, num personagem querido. 
Atrás do ou junto com o trabalho de linguagem e a movência carnal do canto encontramos uma pesquisa aguda.

É um jogo entre unidade e movência, e entre o visto e a voz, que saudamos na arqueologia da poesia mallarmeana, que se diz canto ${ }^{99}$, e que não parece se resumir aos textos escritos, mas compreender como letra e música o simples estado desperto.

\section{Referências bibliográficas}

BAHIR, The. Illumination. Attributed to Rabbi Nehunia ben Hakana, master of the first century esoteric school. Translation, Introduction and Commentary by Arieh Kaplan. Boston: WeiserBooks, 1989 (first published in 1979).

BENJAMIN, Walter. O conceito de crítica de arte no romantismo alemão. Tradução, Introdução e Notas de Márcio Seligman-Silva. 3. ed. São Paulo: Iluminuras, 2002.

BLANCHOT, Maurice. L'entretien infini. Paris: Gallimard, 1969. 1981.

COHN, Robert Greer. Igitur. Berkeley, Los Angeles, London: University of California Press,

D'OLIVET, Fabre. La langue hébraïque restituée et le véritable sens des mots hébreux. Paris: D'Olivet, 1815.

HOFFMAN, Edward. The kabbalah deck. San Francisco/CA: Chronicle books, 2000.

HUTIN, Serge. A alquimia. São Paulo: Moraes, 1992.

mallarmé, S. Euvres Complètes. Org. par Bertrand Marchal. Vol. 1 e 2. Paris: Gallimard, Bibliothèque de la Pléiade, 1998, 2003. (abreviações: Oc1 e Oc2) Autêntica, 2010 .

Rabiscado no Teatro. Tradução e notas de Tomaz Tadeu. Belo Horizonte:

Igitur ou a loucura de Elbehnon. Tradução de José Lino Grunewald. In

Poemas. Rio de Janeiro: Nova Fronteira, 1990.

. Manuscrits d'Igitur, à la Bibliothèque Jacques Doucet, Paris, 2009.

REHFELD, Walter I. Tempo e Religião. São Paulo: Perspectiva/Edusp, 1988.

RENEVILLE, R. de (1948). L'expérience poétique. Genève : A la Baconnière, 1938.

SÊFER IETSIRÁ. O Livro da Criação. São Paulo: Séfer, 2002.

SORVAL, Gérard de. Le langage secret du blason. Paris: Albin Michel, 1981.

\section{Notas de fim}

\footnotetext{
${ }^{1}$ Pós-doutoranda no IEL/UNICAMP com bolsa da CAPES e supervisão de Marcos Siscar; pesquisadora do Brépols brasileiro franco-brasileiro e outros manuscritos, projeto temático subvencionado pela FAPESP e coordenado por Philippe Willemart, USP.

2 Igitur ou a Loucura de Elbehnon.

3 "O lance de dados".

4 "Ele deixa o quarto".

5 "mais tacite encore l'immortelle parole" (Crise de Vers, Oc2:208). "mas tácita ainda a imortal palavra).

${ }^{6} \mathrm{O}$ conto foi escrito entre 1869/1870; o Dr. E. Bonniot o encontrou em 1920 e o publicou em 1925.

7 "Reverencio a opinião de Pọe, nenhum vestígio de uma filosofia, a ética ou a metafísica transparecerá; acrescento que ela é necessária, inclusa ou latente. Evitar alguma realidade de andaime ao redor desta arquitetura espontânea e mágica, não implica a falta de possantes cálculos e sutis; mas nós os ignoramos, eles mesmos se fazem, misteriosos de propósito. O canto jorra de fonte inata, anterior a um conceito, tão puramente que refletir, de fora, mil ritmos de imagens. Que gênio para ser um poeta; que raio de instinto encerrar, simplesmente a vida, virgem, em sua sintese e longe iluminando tudo. A armadura intelectual do poema se dissumula e se sustenta tem lugar - no espaço que isola as estrofes e entre o branco do papel; significativo silencia que não é menos belo compor, que os versos". (Oc2, 659). As traduções das passagens de Mallarmé aqui feitas têm um caráter provisório.

8 "possantes cálculos e sutis; mas nós os ignoramos, eles mesmo se fazem, misteriosamente de propósito."
} 
9 "esquecimento".

${ }^{10}$ Vale ler a transcrição do manuscrito dessa passagem em Oc1, p. 1050-1. Veja-se, por exemplo, no início da página 1051, um trecho que foi eliminado, referindo-se aos "possantes cálculos: "eux mêmes se passent au fond de nous, refoulés, muets" ("eles mesmos se passam no fundo de nós, recalcados, mudos".

1 "Nada terá tido lugar senão o lugar", de Um lance de dados. Oc1, p. 384-385

12 "É o sonho puro de uma Meia-Noite, em si desaparecida [...] senão que subsiste ainda o silêncio de uma antiga palavra proferida por ela". (Oc1, 484).

13 Passagens dessas considerações introdutórias podem ser encontradas em ensaios que já publicamos, como Crítica genética e intertextualidade em Igitur, de Mallarmé In: Criação em debate. Săo Paulo : Humanitas, 2007, p. 193-214.

14 "[...] ocupo-me da armadura de minha obra, que é em prosa. Estivemos tão atrasados, do lado Pensamento, que não passei menos de dez anos a edificar o meu." (Oc1, p. 780).

15 "Infelizmente, escavando o verso a este ponto, encontrei dois abismos, que me desesperam. Um é o Nada [o Vazio], ao qual cheguei sem conhecer o Budismo." (Oc1, p. 696)

${ }^{16}$ Notas sobre a linguagem.

17 "Com efeito, o trabalhador lê poucas obras feitas. O nosso mergulha de bọa vontade nos antigos autores da renascença ou do romantismo que foram seus mestres privilegiados. Ademais, ele gosta da historia - gosto de passado." (Oc1, p. 510).

18 "meu pensamento se pensou e cheguei a uma concepção pura". (Oc1, p. 713).

${ }^{19} \mathrm{Cf}$. “C'est là, je l'ai noté en commençant, l'un des pressentiments les plus hardis du romantisme: la recherche d'une forme nouvelle d'accomplissement qui mobilise - rende mobile - le tout en l'interrompant et par les divers modes de l'interruption. Cette exigence d'une parole fragmentaire, nọn pas pour gêner la communication, mais pour la rendre absolue, c'est ce qui fait dire à Schlegel que seuls les siècles futurs sauront lire les 'fragments' ou bien à Novalis: L'art d'écrire des Livres n'est pas encore découvert, mais il est sur le point de l'être: des fragments, comme ceux-ci, sont des semences littéraires." (Blanchot, 1969, p. 525-526).

20 "incapaz de se mover".

${ }^{21}$ Expressões de Igitur são também bastante hegelianas e a presença de Hegel deveria ser pesquisada.

$22 \mathrm{O}$ felibrismo é uma associação que foi fundada em 1854 por sete amigos, tendo à frente Frédéric Mistral, com o objetivo de proteger e promover a língua d'oc e sua literatura, no sul da França.

${ }^{23} \mathrm{O}$ livro do nada.

24 "as poucas equações sumárias de toda fantasia". (Divagações, Oc2, p.173).

25 "À única inquietação de viajar" (Oc1, p.40-41).

${ }^{26} \mathrm{Oc} 1$, p. 474.

1 - A Meia-Noite.

2 - A escada

3 - O lance de dados.

4 - O sono sobre as cinzas, depois da vela soprada

27 "Adeus, Noite, que fui, teu próprio sepulcro, mas que, a sombra sobrevivente, se metamorfoseará em Eternidade." (Oc1, p. 484).

28 "Depois - como ele terá falado segundo o absoluto." (Oc1, p.837).

29 "Ele deixa o quarto e se perde nas escadas (em vez de descer a cavalo sobre a rampa)". (Oc1, p. 484)

${ }^{30}$ Deixaremos de fora a parte Vie d'Igitur, a ser reintegrada numa análise futura.

${ }^{31}$ Cf. primeiro parágrafo de Oc1, p. 485.

32 "cessação; como se a queda total que tinha sido o choque único das portas do túmulo, não sufocasse o hóspede sem retorno". (Oc1, p. 485).

33 "se apresenta [também à sombra, portanto] uma visão da queda interrompida dos painéis, como se fosse simesmo que, dotado do movimento suspendido o retornasse sobre si na espiral vertiginosa consequente", até que "uma opressão progressiva [...] tivesse implicado a evasão certa num intervalo, a cessação." (Oc1, p. 485).

34 "câmera [ou quarto] de tempo". (Oc1, p.483).

35 "A Meia-Noite.

36 "Painel".

37 (Petit Robert.) Textos em francês que não pertençam a Mallarmé serão diretamente traduzidos no corpo do texto.

38 "A noção de um objeto, escapante, que faz falta". (A Música e as Letras, Oc2, p. 68)

39 "Pois, para o arquejo que roçagara este lugar, não era alguma dúvida última de si, que remexia suas asas por acaso ao passar, mas a fricção familiar e contínua de uma idade superior, da qual vário e vário gênio foi cioso de recolher toda a poeira secular em seu sepulcro para mirar-se em um si próprio, limpo, e que nenhuma suspeita remontava o fio aracnídeo - para que a sombra última se mirasse em seu próprio/limpo si, e se reconhecesse na turba de suas aparições compreendidas pela estrela nacarada de sua nebulosa ciência retida numa das mãos, e pela centelha de ouro do fecho heráldico de seu volume na outra; do volume de suas noites; tais, no presente, vendo-se para que ela se veja, ela, pura, a Sombra, tendo sua última forma que ela pisa, atrás dela, deitada e estendida, e 
depois, diante dela, nesse poço, a extensão de camadas de sombra, devolvịda à noite pura, de todas as suas noites igụais aparecidas, de camadas para sempre separadas delas e que sem dúvida não conheceram - que não é, eu o sei, senão o prolongamento absurdo do ruído da fechadura da porta sepulcral cuja entrada deste poco recorda a porta." Note-se que "propre", em francês, denota "próprio" e também "limpo". Para algumas das soluções da tradução, ainda provisória, de Igitur, baseamo-nos em José Lino Grunewald.

40 "eu o sei".

41 "neste poço".

42 "deste poço".

43 “o intervalo esperado, tendo, em efeito, por paredes laterais, a oposicão dupla dos painéis, e por face à face, à frente e atrás a abertura de dúvida nula, repercutida pelo prolongamento do ruído dos painéis [...]». (Oc1, p. 486)

44 "Era a consciência de si (à qual o absurdo mesmo deveria servir de lugar) - (seu sucesso)." (Oc1, p. 486).

45 Sugestão da caverna de Platão?

46 "se apresenta igualmente numa e noutra face das paredes luzentes e seculares guardando dela apenas, numa das mãos, a claridade opalina de sua ciência e, na outra seu volume, o volume de suas noites agora fechado; do passado e do futuro que chegada ao pináculo de mim, a sombra pura domina perfeitamente, e findos, fora deles. Enquanto que à frente e atrás se prolonga a mentira explorada do infinito, trevas de todas as minhas aparicões reunidas, agora que o tempo cessou e não mais as divide, retombadas num pesado sono, macico (quando do ruído no início escutado), no vazio do qual escuto as pulsações de meu próprio coração.” (Oc1, p. 486).

47 "e que do Infinito se separam e as constelações e o mar, permanecidos, na exterioridade, recíprocos nadas, para lá deixar a essência, à hora unida, fazer o presente absoluto das coisas". (Oc1, p. 483).

48 "Não gosto deste ruído: esta perfeição de minha certeza me incomoda : tudo é demasiado claro, a claridade mostra o desejo de uma evasão; tudo é por demais luzente, eu gostaria de entrar em minha Sombra incriada e anterior [...] ». (Oc1, p. 850). Logo em seguida, o coracão batendo aparece como "o único resto de ambiguidade". uma nova e mais profunda etapa da despersonalização e necessária.

49 "Tal é a marcha inversa da noção da qual ele não conheceu a ascensão, tendo, adolescente, chegado ao Absoluto, incapaz de mover-se." (Oc1, p.481).

${ }^{50}$ No último parágrafo de "Il quitte la chambre”, o narrador-personagem dirá: "C'était le scandement de ma mesure" (Oc1, p. 487). ("Era a escansão de minha medida").

51 "Com efeito, a primeira vinda assemelha-se à espiral precedente: mesmo ruído escandido, - e mesmo roçagar". (Oc1, p.486).

52 "Essa escansão não era o ruído do progresso de meu personagem que agora o continua na espiral, e este roçagar, o roçagar incerto da dualidade?" (Oc1, p. 487).

53 "À quelque amphithéatre, comme une aile d'infinité humaine, bifurque la multitude, effarouchée devant le brusque abime fait par le dieu, 1'homme - ou Type." (Oc2, p. 240, "Catholicisme"). "Em algum anfiteatro, como uma asa da infinitude humana, bifurca a multidăo, espantada frente ao brusco abismo feito pelo deus, o homem ou Tipo." Type tira aqui partido de sua dupla acepção de elemento gráfico e homem modelar: o homem-letra, inscrito.

54 "Outro esboço".

55 “"...] c'est le froissement de la lueur de ma conscience sur le buste revêtu de velours qui veut redevenir obscurité pure d'un hôte supérieur dont j'ai pris la forme." (Oc1, p. 496) "[...] é o amarfalhar do clarão de minha consciência sobre o busto revestido de veludo que quer voltar a ser obscuridade pura de um hóspede superior do qual tomei a forma."

${ }^{56} \mathrm{O}$ manuscrito aqui parece propositalmente ambíguo, as duas possibilidades valendo.

57 "então, agora que sua dualidade está para sempre separada [ou : nunca está separada], e que não escuto nem mesmo através dele o ruído de seu progresso, vou me esquecer através dele, e me dissolver em mim." (Oc1, p. 487)

58 Sobre essa prisão no quarto, da qual o protagonista busca sair, é o próprio conto que fala em outra parte, numa frase já citada: "Telle est la marche inverse de Ta notion dont il n'a pas connu l'ascension, étant, adolescent, arrivé à l'Absolu, incapable de bouger" (Oc1, p.481).

59 "O lance de dados" (que não deve ser confundido com o poema Um lance de dados, de 1896).

60 "Ele profere a predição, da qual se ri no fundo. Houve loucura."

61 "o silêncio de uma antiga palavra proferida por ele", em "A Meia-Noite".

62"Ele deixa o quarto."

63 "Hasard" em francês quer dizer "acaso" ou "azar", "sorte.

64 "Espiritualizar o corpo e corporificar o espírito" é um lema alquímico tradicional.

65 Painel.

${ }^{66}$ Sobre a pedra filosofal, ela é o que transforma o vil metal em ouro, e "Tem a propriedade de suscitar a forma e de a perfazer até o infinito, porque a parte de substância melhorada melhora a seguinte e assim sucessivamente até ao infinito" (Arnauld de Villeneuve apud Hutin, p. 76).

67 "Houve Loucura".

${ }^{68}$ Cf. Rehfeld, Walter I. (1988). Tempo e Religião. São Paulo: Perspectiva/Edusp, p. 92-93.

${ }^{69}$ Oc1, p. 484. Nessa página de "Le Minuit", quatro linhas depois de "une antique parole", lemos "une antique antique". Mas talvez haja um sentido em Mallarmé usar « antique » e não « ancienne », que é normalmente o 
atributo da « palavra » no mito maçon.

${ }^{70}$ Para que aquela fosse guardada intacta, impronunciável por quem não tinha competência interior para tal.

${ }^{71}$ Poderíamos examinar com proveito em outro momento as sugestões de "Mi", em "Minuit".

72 "Ele profere a predição, da qual se ri no fundo. Houve loucura. "

73 Segue um trecho dela: "Depuis longtemps morte, une antique idée [...] se reconnaît à l'immémorial geste vacant avec lequel elle s'invite ") (Ocl, p. 484). Para as relaçoes entre o Verbo e a Linguagem ("Ne jamais confondre le Langage avec le Verbe", Oc 1, p. 505), bem como entre o Verbo e a negação, devem-se analisar as notas de "De divinitate", em Notes sur le langage (Oc1, p. 503-512).

74 "Eis aí, constatação à qual deslizo, como, em nossa língua, os versos não vão senão aos pares ou em vários, em razão de seu acordo final, seja a lei misteriosa da Rima, que se revela na função guardiã e de impedir que entre todos, um usurpe, ou permaneça peremptoriamente: em qual pensamento fabricado aquele! pouco me importa, uma vez que sua materia discutível imediatamente, gratuita, não produziria prova a se sustentar num equilíbrio momentâneo e duplo à maneira do voo, identidade de dois fragmentos constitutivos rememorada exteriormente por uma paridade na consonância." (Oc2, p. 201, "Solennité", in Crayonné au Théatre) [Baseamo-nos aqui, em boa parte, na tradução de Tomaz Radeu, in Mallarmé, S.. Rabiscado no teatro. Belo Horizonte: Autêntica, 2010, p. 107.]

75 "À única inquietação de viajar".

76 "Noite, desespero e pedraria".

77 Brinde ("solitude, recife, estrela").

78 "Certamente subsiste uma presença de Meia-Noite. »

79 "É o sonho puro de uma Meia-Noite, em si desaparecida, [...] a menos que subsista ainda o silêncio de uma antiga palavra proferida por ela."

80 "Adeus, Noite, que eu fui, teu próprio sepulcro, mas que, a sombra sobrevivente, se metamorfoseará em Eternidade"

81 "[...] o infinito está enfim fixado.

salvo que movimento (pessoal) rendido [devolvido] ao infinito".

82 "Je crois que la Littérature, reprise à sa source qui est l'Art et la Science, nous fournira un Théâtre, dont les représentations seront le vrai culte moderne; un Livre, explication de l'homme, suffisante à nos plus beaux rêves. Je crois tout cela écrit dans la nature de facon à ne laisser fermer les yeux qu'aux intéressés à ne rien voir." "Sur le Théatre", Oc2, p.657) "Creio que a Literatura, retomada em sua fonte que é a Arte e a Ciência, nos fornecerá um Teatro, cujas representações serão o verdadeiro culto moderno; um Livro, explicação do homem, suficiente a nossos mais belos sonhos., Penso tudo isso escrito na natureza de modo a não deixar fechar os olhos senão aos interessados em nada ver."

83 "Desde há muito tempo morta, uma antiga ideia se mira tal à claridade da quimera na qual agonizou seu sonho [e] se reconhece ao imemorial gesto vago com o quale la se convida, pata terminar o antagonism deste sonho polar, a render-se, com e a claridade quimérica e o texto fechado, ao Caos da sombra abortada e da palavra que absolve e absolutiza Meia-Noite."

${ }^{84}$ Agradecemos a Caio Leal, do Laboratório do Manuscrito Literário, por sua lúcida observação.

85 "algum supremo molde não tendo lugar enquanto que de nenhum objeto que existe".

86 "enquanto se imobiliza, (num movente limite), o local anterior da queda da hora numa calmaria narcótica de eu puro longo tempo sonhado." (Oc1, p. 483).

87 "As palavras inglesas".

${ }^{88}$ Em tradução literal, que perde o jogo sonoro-significante: "as cinzas/descer; estrela/véu". (Oc1, p. 866-868).

$89 \mathrm{O}$ terceiro livro mais importante é o Zohar.

90 "tão longe quanto um lugar fusiona com o além". (Oc1, p.386-387)

91 (D’Olivet, 1815, p.37).

92 "Jóia nula de fantasia"; "aos olhos nulos semelhantes ao espelho". (Oc1, p. 483).

${ }^{93}$ Hoffman, Edward. The kabbalah deck. San Francisco/CA: Chronicle books, 2000, p. 16. Livro em inglês, tradução nossa.

94 (D’Olivet, 1815, p. 18, "Racines Hébraiques".)

95 Cf. D’Olivet, 1815 , p. 19 do cap. II.

${ }^{96}$ No Cristianismo, metáfora do Cristo, arquétipo do Homem, do Tipo, em Mallarmé. A imagem corpórea e a letra amáveis não são excludentes em sua oḅra, antes complementares, mesmo que em certo ponto do trajeto a palavra deva matar sim a imagem, que ressuscitará necessária mais adiante.

97 “a letra - o equivalente da Ficção". (Mallarmé, 1998, p.503).

98 "Il jette les dés, le coup s'accomplit, douze, (le temps (Minuit) - qui créa se retrouve la matière, les blocs, les dés." (Oc1, p. 482). "Ele joga os dados, o lance se cumpre, doze, (o tempo (Meia-Noite) - que criou se reencontra a materia, os blocos, os dados."

${ }^{99}$ Em vários textos, como por exemplo, indiretamente, no poema Au seul souci de voyager. 